\title{
Using GMDH Neural Networks to Model the Power and Torque of a Stirling Engine
}

\section{Mohammad Hossein Ahmadi ${ }^{1, *}$, Mohammad-Ali Ahmadi ${ }^{2}$, Mehdi Mehrpooya $^{1}$ and Marc A. $\operatorname{Rosen}^{3}$}

${ }^{1}$ Department of Renewable Energies, Faculty of New Science and Technologies, University of Tehran, Tehran, Iran

${ }^{2}$ Department of Petroleum Engineering, Ahwaz Faculty of Petroleum Engineering, Petroleum University of Technology (PUT), Ahwaz, Iran

${ }^{3}$ Faculty of Engineering and Applied Science, University of Ontario Institute of Technology, 2000 Simcoe Street North, Oshawa, Ontario, L1H 7K4, Canada

E-Mails: mohammadhosein.ahmadi@gmail.com; ahmadi6776@yahoo.com; Mehdi Mehrpooya; Marc A. Rosen

* Author to whom correspondence should be addressed; Tel.: +989122866205

Received: 14 August 2014 / Accepted: 31 October 2014 / Published: 3 November 2014

\begin{abstract}
The Stirling engine is an external-combustion engine that utilizes a compressible working fluid. The Stirling engine can be very efficient, having the same theoretical energy efficiency as the Carnot engine for transforming heat to work. It is environmentally advantageous and can mitigate $\mathrm{CO}_{2}$ emissions from combustion. Various parameters affect the performance of the Stirling engine and are considered in optimization and designing activities. Among these factors, torque and power have the greatest effect on the robustness of the Stirling engine, so they need to be determined with low uncertainty and high precision. In this article, the distribution of torque and power are determined using experimental data. Specifically, a novel polynomial approach is proposed to specify torque and power, on the basis of previous experimental work. This research addresses the question of whether GMDH (group method of data handling)-type neural networks can be utilized to predict the torque and power based on determined parameters.
\end{abstract}


Keywords: GMDH; Neural Network; Stirling Engine; Torque, Power

\section{Introduction}

Reducing use of fossil fuels is a significant energy quests of today's world, and many researchers are seeking ways to harness alternative energy resources and developing enhanced energy conversion systems.

An important energy conversion system which can contribute to these goals is the Stirling engine, which can generate electrical power with high thermal efficiency. It is an external combustion engine which works within an extensive temperature interval and provides opportunity of enhanced combustion control. Stirling engines works utilize expansion and compression processes of a working fluid (e.g., gases such as hydrogen, helium and air ) [1,2]. The efficiency of a Stirling engine varies with charge pressure, mechanical connections, temperature difference between the cold and hot reservoirs, regenerator efficiency, heat transfer coefficient, impermeability ratio and physical and thermal properties of the working fluid (e.g., thermal conductivity, viscosity, heat capacity) [3].

Many efforts at manufacturing and enlarging of Stirling engine have been put forth by companies and research organizations. The period of new Stirling engine improvement was began in 1937 by the Philips Company, which developed Stirling engine sizes up to $336 \mathrm{~kW}$ [4]. More recently, Prodesser [5] built a Stirling engine that is fueled with biomass to produce electric power, and that can generate an electric power of $3.2 \mathrm{~kW}$ while achieving a pressure of 33 bars. Sripakagorn and Srikam [6] built a beta-type Stirling engine that operated at a medium temperature range and generated $95.4 \mathrm{~W}$ of electric power with internal conditions of $773 \mathrm{~K}$ and 7 bar. Karabulut et al. [7] built a Stirling engine capable of generating $183 \mathrm{~W}$ of electric power using a working fluid of helium that attains a pressure of 4 bar. Cheng and $\mathrm{Yu}$ [8] investigated numerically a beta-type Stirling engine to identify the effects of various parameters, including non-isothermal effects and the performance of the regenerative channel. Chen et al. [9] developed a numerical approach for assessing a c-type Stirling engine so as to permit prediction of various geometrical and process characteristics, and showed that regeneration effectiveness influences efficiency and engine speed influences engine power the most. Formosa and Despesse [10] developed a model to investigate heat exchanger efficiency and regenerator flaws for a Stirling engine, and examined the effects of regeneration on thermal efficiency and output power. Also, a smart model to predict Stirling heat engine power output using an evolutionary approach was developed by Ahmadi et al. [11-17].

System identification methods are able to demonstrate and estimate the behaviors of unidentified and/or very complicated systems on the basis of specified input-output data, for various fields of engineering [18]. Calculation approaches for these methods [19], which involve specification in an uncertain environment, have attracted considerable attention of researchers. The most common calculation approaches include neural networks, fuzzy logic and evolutionary algorithms, and these have contributed significantly to improving understanding of recognition and control issues for complicated, non-linear systems. 
Various investigations have been performed on methods for utilizing evolutionary algorithms for system recognition [20-24]. Amongst these, the group method of data handling (GMDH) is a selforganizing technique that creates a progressively more complex approach on the basis of the assessment of its effectiveness for an assortment of multi-input, single-output data couples (Xi,yi) ( $\mathrm{i}=$ $1,2, \ldots, \mathrm{M})$. The GMDH was introduced by Ivakhnenko [25] as a multivariate analysis approach for complicated systems modeling and recognition. GMDH can be utilized to avoid the complexity of obtaining former information with the algebraic approach of the progression. Thus, GMDH can be utilized to demonstrate complicated systems without having particular information of the systems.

GMDH operates by creating an analytical function in a feed forward network on the basis of a quadratic node transfer function [26], in which constants are obtained by a regression procedure. The actual GMDH approach, where method factors are approximated via a least squares approach, can be categorized based on comprehensive initiation and partial initiation; illustrate the combinatorial (COMBI) and multi-layered iterative algorithms (MIA), correspondingly [27].

Presently, the employment of self-organizing networks has increased the effectiveness of the GMDH approach for a wide variety of fields and applications [25-31]. There have been many attempts in the past to assemble population-based stochastic search methods such as evolutionary approaches like ANNs (artificial neural network), particularly since such evolutionary methods are helpful for complicated problems having large search spaces with many local optimums [32]. A review of evolutionary approaches within ANNs is presented in Ref. [33]. Genetic algorithms have been utilized in feed-forward GMDH style NNs, in which a neuron explores its optimum assortment of connections with the previous layer [34].

In the present work, a model is developed incorporating GMDH and Stirling engine experimental outcomes for the first time $[35,36]$. The results are verified against experimental values. In the study, 112 configuration numbers, obtained from prior investigations [35,36], are utilized for both training the polynomial NN and estimation. Inputs for the NN model are temperature of the hot working fluid, pressure and fuel, while the outputs are torque and power. The GMDH-style NN is developed to determine the input-output relationship in the form of polynomials. Such NN recognition progression requires some optimization approaches to specify the best network topology. In this regard, the GAs are organized in a novel model to specify the complete topology of the GMDH-style NNs, i.e., the neurons' number throughout every hidden layer and their connection conformation. Singular Value Decomposition (SVD) is employed to identify the optimum constants of quadratic formulations for predicting of torque and power.

\section{Principles of modeling using GMDH types of Artificial Neural Networks}

An approach can be expressed as an assortment of neurons where various pairs throughout every layer are associated via a quadratic polynomial through the GMDH algorithm and, consequently, generate fresh neurons throughout the further layer. Such information can be used in modeling to link outputs to inputs. The accepted definition of the recognition issue is to determine a function $\hat{f}$ that can be roughly utilized in place of real one, $t$, with the intention of estimating output $\hat{y}$ for a specified 
input vector $X=\left(x_{1}, x_{2}, x_{3}, \ldots, x_{n}\right)$ that is close to its real output $\mathrm{y}$. For specified $\mathrm{M}$ observations of multi-input-single-output data couples the real target can be expressed as follows:

$$
y_{i}=f\left(x_{i 1}, x_{i 2}, x_{i 3}, \ldots, x_{i n}\right) \quad(i=1,2,3, \ldots M)
$$

Now, a GMDH style NN is trained to estimate the target values $\hat{f}_{i}$ for any specified input vector $X=\left(x_{i 1}, x_{i 2}, x_{i 3}, \ldots, x_{i n}\right)$ as follows:

$$
\hat{y}_{i}=\hat{f}\left(x_{i 1}, x_{i 2}, x_{i 3}, \ldots, x_{i n}\right) \quad(i=1,2,3, \ldots M)
$$

In this step, the issue is to specify a GMDH style NN in order to minimize the square of the difference between the real target and the estimated one, as follows:

$$
\sum_{i=1}^{M}\left[\hat{f}\left(x_{i 1}, x_{i 2}, x_{i 3}, \ldots, x_{i n}\right)-\hat{y}_{i}\right]^{2} \rightarrow \min
$$

The overall relation between input and output parameters can be formulated by a complex discrete form of the Volterra functional series as follows:

$$
y=a_{\circ}+\sum_{i=1}^{n} a_{i} x_{i}+\sum_{i=1}^{n} \sum_{j=1}^{n} a_{i j} x_{i} x_{j}+\sum_{i=1}^{n} \sum_{j=1}^{n} \sum_{k=1}^{n} a_{i j k} x_{i} x_{j} x_{k}+\ldots
$$

which is recognized as the Kolmogorov-Gabor polynomial [25,27-29]. This full algebraic arrangement can be represented by a system of partial quadratic polynomials containing only two parameters (neurons) as follows:

$\hat{y}=G\left(x_{i}, x_{j}\right)=a_{\circ}+a_{1} x_{i}+a_{2} x_{j}+a_{3} x_{i}^{2}+a_{4} x_{j}^{2}+a_{5} x_{i} x_{j}$

In this regard, such partial quadratic sketch is utilized reversely throughout a network of linked neurons to form the universal arithmetic correlation of input and output parameters specified in Eq. (4). The coefficients $a_{i}$ in Eq. (5) are specified by regression approaches in order to minimize the differentiation between real output $y$ and the determined one $\hat{y}$ for each pair of input parameters $x_{i}, x_{j}$.

In actuality, it can be observed that a hierarchy of polynomials is built utilizing the quadratic form provided in Eq. (5) whose constants are acquired via least-squares logic. Then, the constants of every quadratic function $G_{i}$ are obtained to optimally fit the output throughout the entire set of output-input data pairs, as follows:

$$
E=\frac{\sum_{i}^{M}\left(y_{i}-G_{i}\right)^{2}}{M} \rightarrow \min
$$

In simple terms, in the GMDH approach the probabilities are provided of two autonomous parameters out of the entire $\mathrm{n}$ input parameters being chosen. This is done with to create the regression 
polynomial in Eq. (5) that best fits the dependent observations $\left(y_{i}, i=1,2, \ldots, M\right)$ through leastsquares logic.

Accordingly, $\left(\begin{array}{l}n \\ 2\end{array}\right)=\frac{n(n-1)}{2}$ neurons are assembled throughout the prime hidden layer of the feed forward NN from the observations $\left\{\left(y_{i}, x_{i p}, x_{i q}\right) ;(i=1,2, \ldots, M\}\right.$ for various $p, q \in\{1,2, \ldots, n\}$. That is, it is now promising to build $M$ data trebles $\left\{\left(y_{i}, x_{i p}, x_{i q}\right) ;(i=1,2, \ldots, M\}\right.$ from observations utilizing such $p, q \in\{1,2, \ldots, n\}$ sets as follows:

$$
\left[\begin{array}{lll}
x_{1 p} & x_{1 q} & y_{1} \\
x_{2 p} & x_{2 q} & y_{2} \\
x_{3 p} & x_{3 q} & y_{M}
\end{array}\right]
$$

Utilizing the quadratic sub-formulation type of Eq. (5) for every row of $M$ data trebles, the subsequent matrix formula can be straightaway gained as

$$
\begin{aligned}
& A a=Y \\
& a=\left\{a_{\circ}, a_{1}, a_{2}, a_{3}, a_{4}, a_{5}\right\} \\
& Y=\left\{y_{1}, y_{2}, y_{3}, \ldots y_{M}\right\}^{T}
\end{aligned}
$$

Here, $a$ denotes for the vector of unidentified constants for the quadratic polynomial in Eq. (5), and $Y$ denotes the vector of output values from observations. Thus, the following expression can be formulated:

$$
A=\left[\begin{array}{cccccc}
1 & x_{1 p} & x_{1 q} & x_{1 p} x_{1 q} & x_{1 p}^{2} & x_{1 q}^{2} \\
1 & x_{2 p} & x_{2 q} & x_{2 p} x_{2 q} & x_{2 p}^{2} & x_{2 q}^{2} \\
\hdashline 1 & x_{M p} & x_{M q} & x_{M p} x_{M q} & x_{M p}^{2} & x_{M q}^{2}
\end{array}\right]
$$

The least-squares approach from the analysis of the multiple-regression effect leads to the following standard expression:

$$
a=\left(A^{T} A\right)^{-1} A^{T}
$$

This equation specifies the vector of the best constants of Equation (5) for the entire array of M data trebles. Note that this technique is iterated for every neuron of the further hidden layer accompanied by the connectivity structure of the NN. Such an answer from standard equations is more exactly vulnerable to improve deviations and, more outstandingly, to the individuality of the aforementioned formulas [37-42].

There are two central concepts included in a GMDH type of artificial neural network scheme, i.e., topology identification and the parametric [37-42] utilization of the GA for designing the structure for GMDH type of NNs. Stochastic techniques are generally utilized throughout the process of training of 
NNs in terms of connected coefficients or weights, and have been effectively implemented and demonstrated to be superior to conventional gradient-based approaches.

In the most GMDH types of NNs, neurons throughout any layer are linked to a neuron in a neighboring layer, as indicated earlier for techniques I and II that previously report in [30-35]. With this improvement, a straightforward programming pattern can be used for the genotype of any individual throughout the population, as previously suggested [33, 37, 38]. The programming scheme is presented in Fig. 1.

GMDH NNs (GS-GMDH) should be capable of demonstrating various lengths and sizes of such NNs. throughout a GS-GMDH NN, as demonstrated in Fig. 1, neuron ad inside the principal hidden layer is attached to the output layer by straightforwardly extending the further hidden layer. Thus, it is relatively simple to perceive that the designation of the network's output includes ad double as abbcadad. That is, a cybernetic neuron named adad is assembled throughout the further hidden layer and utilized within the same layer to create the output neuron, as illustrated in the Fig. 1.

Figure. 1. A generalized GMDH network structure of chromosome.

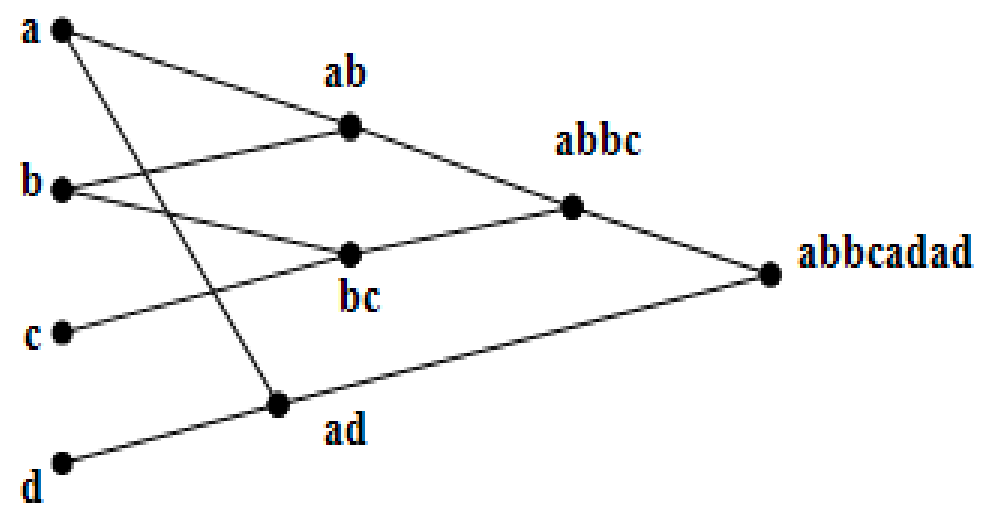

This procedure occurs when a neuron is delivered to particular neighboring hidden layers and links to an alternative neuron in the succeeding hidden layer (2nd, or $3 \mathrm{rd}$, or 4 th, etc.). Throughout this programming pattern, the number of replications that neuron is subject to the number of approved hidden layers, $\widetilde{n}$, and is determined as $2^{\widetilde{n}}$. Note that a chromosome such as ababbcbc, is different from chromosome ababacbc, and thus it is not a usable individual in the GS-GMDH networks and has to be re-written straightforwardly as abbc.

Now it is possible to generate two offsprings from two parents by implementing the GA operatives of mutation and crossover. The process of selection is performed on the basis of a natural roulette wheel selection approach for selecting two parents generating two offsprings $[33,37,38]$.

The combination of a GA into the scheme of GMDH style NNs commences by demonstrating each network as a string of consecutive sub-strings of sequential numbers. The fitness, $\varphi$, of each whole string of representative numbers which characterizes a GMDH style NN approach is assessed as follows:

$$
\phi=\frac{1}{E}
$$


where E denotes the mean square of error (MSE) in Eq. (10), which is minimalized inside the evolutionary progression by exploiting the magnitude of fitness, $\varphi$.

The evolutionary progression is initiated by arbitrarily producing an initial population of representative series, as a proposed solution. Then, genetic operations such as mutation, crossover and roulette wheel selection are performed on the overall population of representative series to improve the solution progressively. In this regard, GMDH style NN approaches with increasingly rising fitness, $\varphi$, are created until no additional substantial progress is possible.

To determine the integrity and reliability of the proposed polynomial models for modeling torque and output power of the Stirling engine, the correlation of determination $\left(R^{2}\right)$, as a mean absolute percentage of error (MAPE), and root mean square error (RMSE) which are used, expressed as follows [43-45]:

$$
\begin{aligned}
& \left.R^{2}=1-\left[\frac{\sum_{i=0}^{M}\left(Y_{i(\text { model })}-Y_{i(\text { Actual })}\right)^{2}}{\sum_{i=1}^{M}\left(Y_{i(\text { Actual })}\right)^{2}}\right]^{2}\right]^{1 / 2} \\
& \left.R M S E=\left[\frac{\sum_{i=0}^{M}\left(Y_{i(\bmod e l)}-Y_{i(\text { Actual })}\right.}{M}\right]^{1 / 2} \mid\right] \\
& M A P E=\left[\frac{\sum_{i=0}^{M}\left|Y_{i(\bmod e l)}-Y_{i(\text { Actual })}\right|}{M \sum_{i=1}^{M}\left(Y_{i(\text { Actual })}\right)}\right]
\end{aligned}
$$

\section{Results and Discussion}

Based on the approach described in the preceding section, the polynomial generated for the Stirling engine for torque is formulated as follows:

$$
\begin{aligned}
& \text { Torque }=4.19018-0.013268 T_{h}-0.00270926 A T_{h}+0.00000990598 T_{h}^{2}+2.8801 A+0.155272 A^{2} \\
& A=-0.189686+2.02653 B-0.930981 B C+0.381378 B^{2}-0.480105 C+0.305945 C^{2} \\
& B=-3.45598+0.00754163 T_{h}+0.000582712 T_{h} p-0.00000502679 T_{h}^{2}-0.0170738 p^{2} \\
& C=-1.45881+0.253347 p+0.0575211 p F-0.0282376 p^{2}+0.441726 F-0.0596564 F^{2}
\end{aligned}
$$

and for output power is formulated as follows: 
Output power $=373.951-1.12004 T_{h}-0.00564667 A^{\prime} T_{h}+0.000785436 T_{h}^{2}+1.50314 A^{\prime}$

$A^{\prime}=20.687+1.51768 B^{\prime}+0.00209829 B^{\prime} C^{\prime}-0.0018406 B^{\prime 2}-0.660555 C^{\prime}$

$B^{\prime}=-638.237+1.30715 T_{h}+0.0842743 T_{h} p-0.000835089 T_{h}^{2}+12.9758 p-3.19127 p^{2}$

$C^{\prime}=-162.822+47.9507 p+5.65611 p F-4.19637 p^{2}+16.5671 F$

Here, $p$ denotes pressure, $T_{h}$ temperature of the hot working fluid, and $F$ fuel. Statistical indices for the results obtained with the aforementioned polynomial approaches are summarized in Tables 1 and 2 for torque and power, respectively.

Table 1. Values of absolute fraction of variance, root-mean squared error and mean absolute percentage, respectively, for torque model.

\begin{tabular}{lc}
\hline Statistical parameter & Value \\
\hline $\mathrm{R}^{2}$ & 0.9518 \\
\hline $\mathrm{MAPE}$ & 0.0007 \\
$\mathrm{RMSE}$ & 0.1718 \\
\hline
\end{tabular}

Table 2. Values of absolute fraction of variance, root-mean squared error and mean absolute percentage, respectively, for power model.

\begin{tabular}{lc}
\hline Statistical parameter & Value \\
\hline $\mathrm{R}^{2}$ & 0.9737 \\
\hline $\mathrm{MAPE}$ & 0.0005 \\
$\mathrm{RMSE}$ & 0.1838 \\
\hline
\end{tabular}

As illustrated in Fig. 2, the deviations for torque values predicted with the model are not considerable when the torque is between 0.1 and $1.5 \mathrm{~N} . \mathrm{m}$, are low when the torque is between 1.5 and 2.5 N.m and approach zero when the torque is between 2.5 and 3.7 N.m. The relative error of the developed ANN model for torque determination versus relevant actual torque values are also shown in Fig. 2, where the maximum relative error is seen to be $32 \%$ for the low torque boundary and to decrease as torque rises, reaching a value of $11 \%$ for high torques. 
Figure 2. Variation of relative error with corresponding experimental torque values.

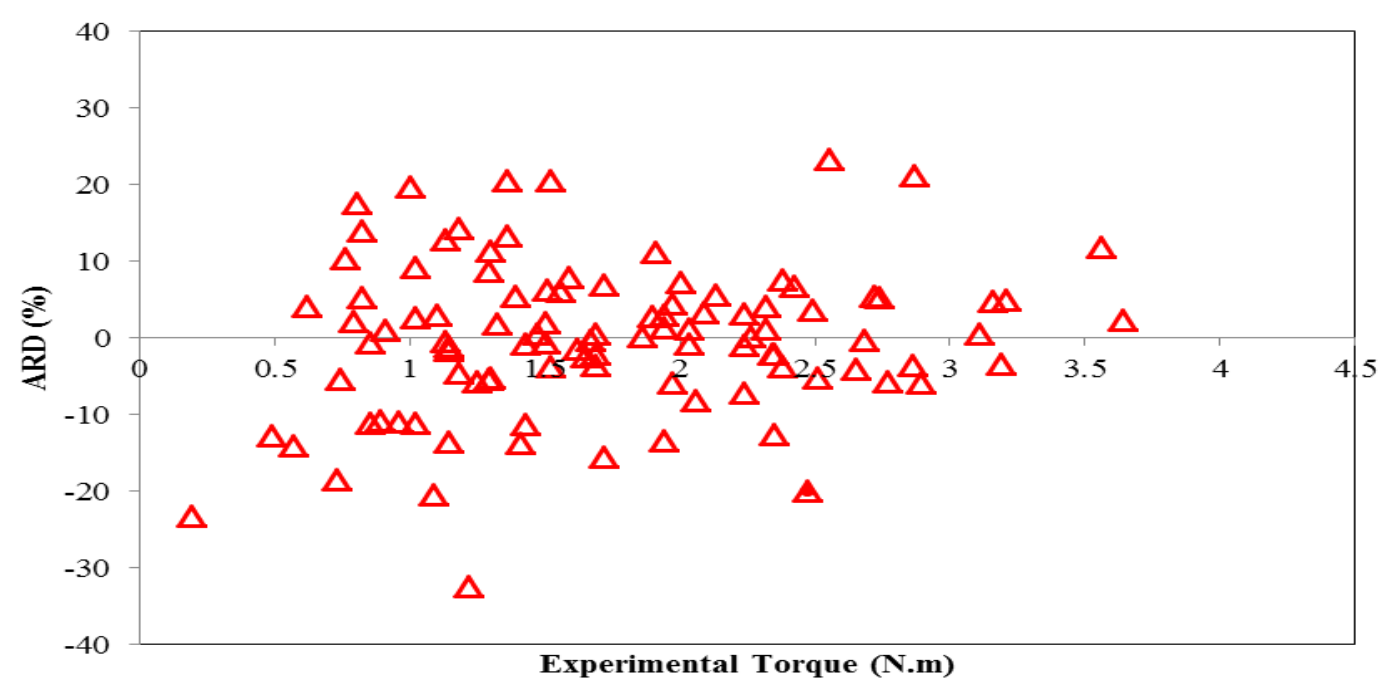

It can be seen in Fig. 3 that there is a good agreement between the model outputs and the experimental torque based on the data index simulated in this work.

Figure 3. Comparison of experimental torque and outcomes of the GMDH approach.

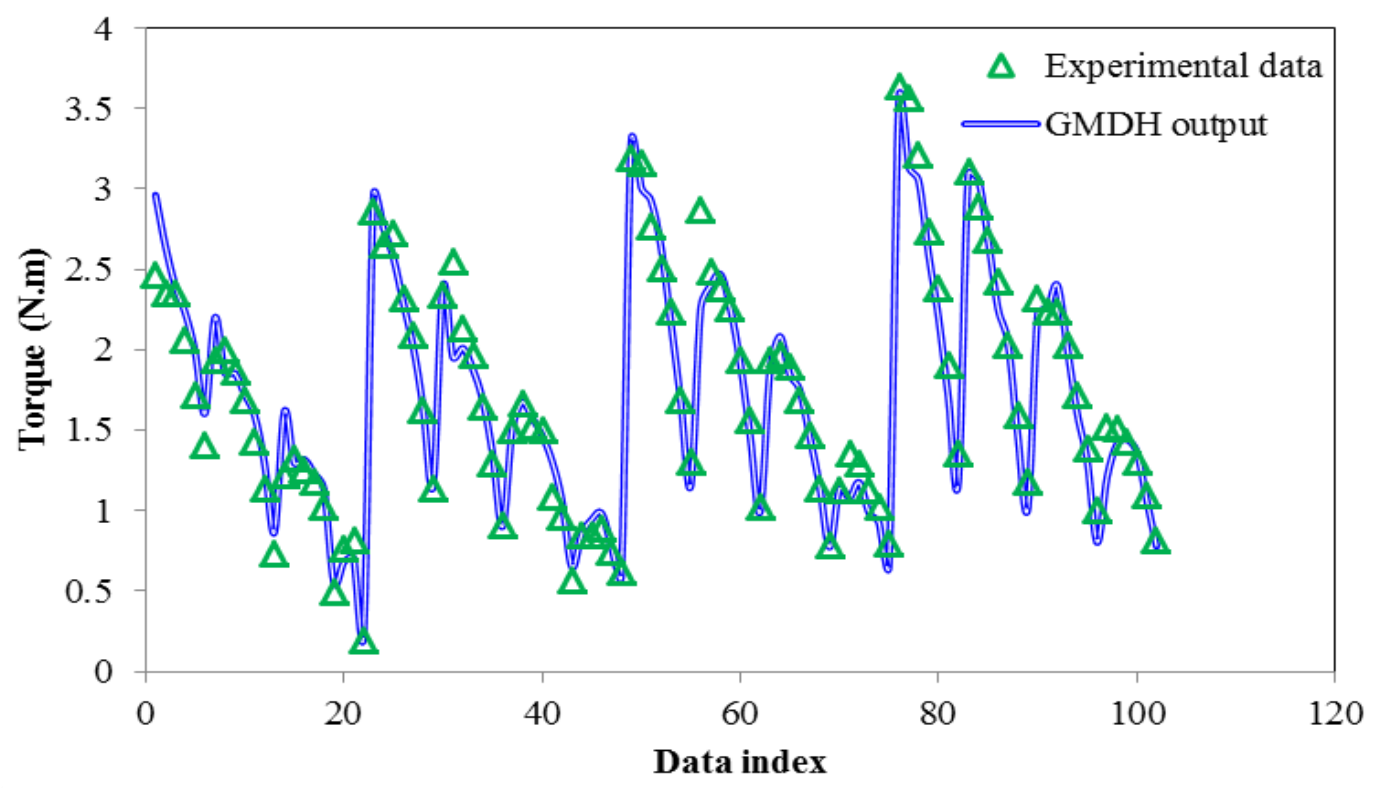

The output results of GMDH model in Fig. 4 for experimental power outputs of $50 \mathrm{~W}$ through 500 $\mathrm{W}$ are compressed around zero deviation line, which means that the deviation of the addressed model in this interval is very low. Nonetheless, about five noisy points experimental power outputs lower than $150 \mathrm{~W}$ are observed in the figure.

Figure 4. Variation of relative error with experimental power output values. 


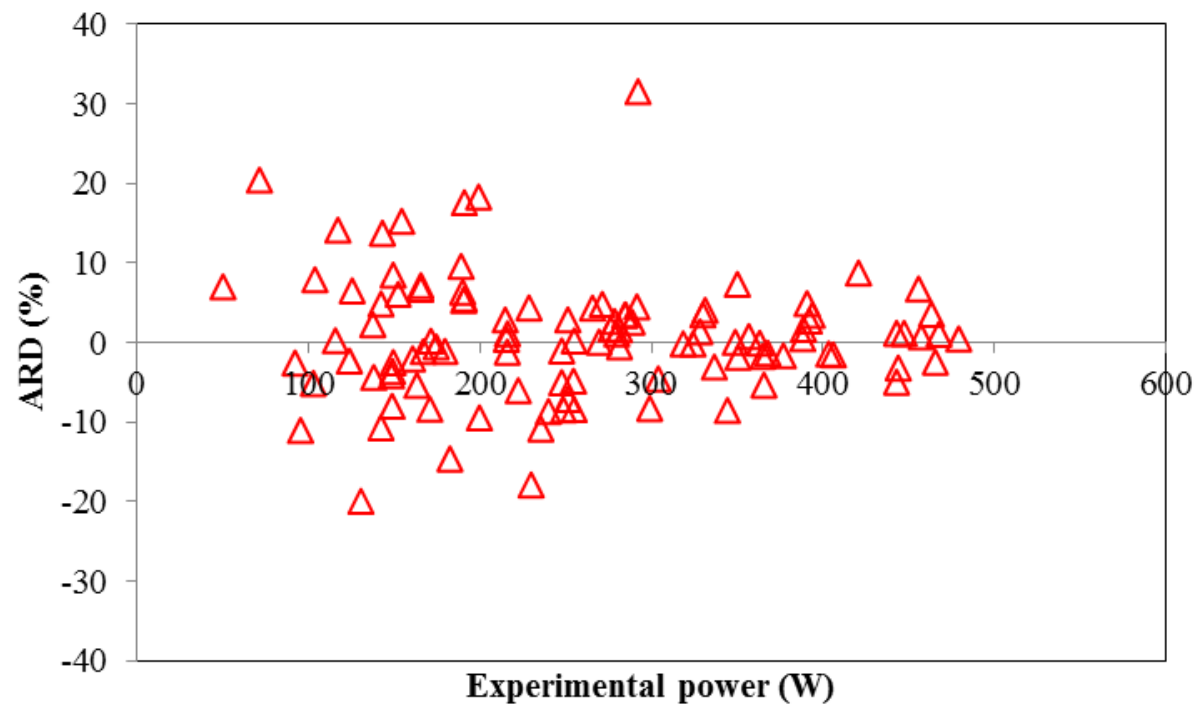

The outcomes of the evolved GMDH model are seen in Fig. 5 to follow the actual trend of the output power of the Stirling engine based on the corresponding data index simulated in this study.

Figure 5. Comparison of experimental power output and outcomes of the GMDH approach.

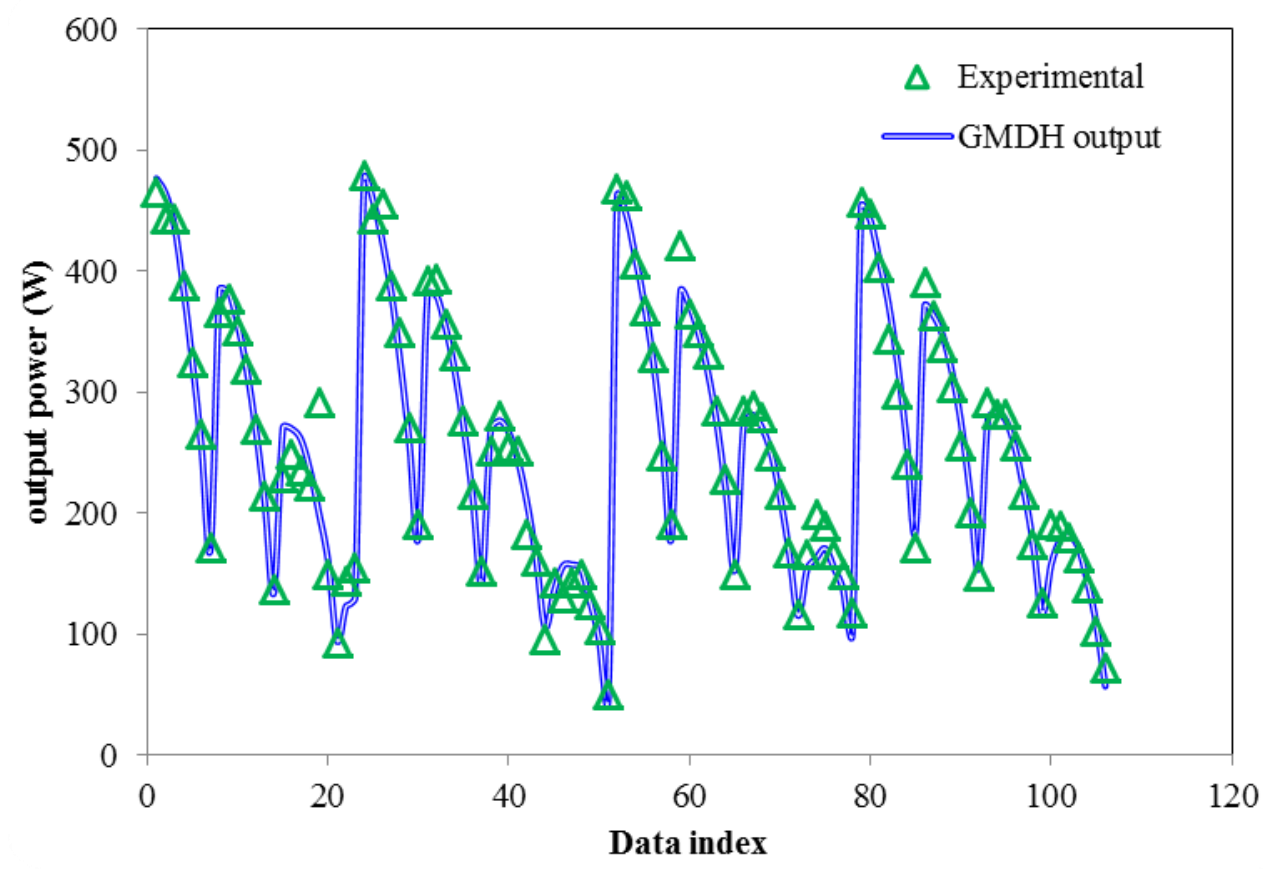

\section{Conclusions}

An intelligent approach to determine the output power and torque of a Stirling heat engine is proposed and developed. The approach exploits the GMDH method to develop an accurate predictive 
tool for determining addressed variables in manner that is inexpensive, fast and precise. Accurate actual data banks used with the predictive tool for testing and optimizing phases. The statistical data regarding the output results of the developed GMDH model suggest that the evolved method has a high level of robustness and integrity for output power and torque determination. Thus, based on the output results, the GMDH approach could help energy experts to design Stirling heat engines with high levels of performance, reliability and robustness and with a low degree of uncertainty.

\section{Conflict of Interest}

The author declares that they have no conflict of interests regarding the publication of this paper.

\section{References and Notes}

1. Shendage DJ, Kedare SB, Bapat SL. An analysis of a beta type Stirling engine with rhombic drive mechanism. Renew Energy 2011, Volume 36, pp.289-97.

2. Thombare DG, Verma SK. Technological development in the Stirling cycle engines. Renew Sustain Energy Rev 2008, Volume 12,pp.1-38.

3. Karabulut H, Yucesu HS, Cinar C. Nodal analysis of a Stirling engine with concentric piston and displacer. Renew Energy 2006, Volume 31, pp.2188-97.

4. Karabulut H, Yucesu HS, Cinar C, Aksoy F. An experimental study on the development of a btype Stirling engine for low and moderate temperature heat sources. Appl Energy 2009,Volume 86,pp.68-73.

5. Prodesser E. Electricity production in rural villages with biomass Stirling engines. Renew Energy 1999, Volume 16, pp.1049-52.

6. Sripakagorn A, Srikam C. Design and performance of a moderate temperature difference Stirling engine. Renew Energy 2011, Volume 36, pp.1728-33.

7. Karabulut H, Cinar C, Ozturk E, Yucesu HS. Torque and power characteristics of a helium charged Stirling engine with a lever controlled displacer driving mechanism. Renew Energy 2010, Volume 35,pp.138-43.

8. Cheng $\mathrm{CH}, \mathrm{Yu}$ YJ. Numerical model for predicting thermodynamic cycle and thermal efficiency of a beta-type Stirling engine with rhombic-drive mechanism. Renew Energy 2010,Volume 35,pp.2590-601.

9. Chen WL, Wong KL, Po LW. A numerical analysis on the performance of a pressurized twin power piston gamma-type Stirling engine. Energy Convers Manag 2012, Volume 62, pp.84-92.

10. Formosa F, Despesse G. Analytical model for Stirling cycle machine design. Energy Convers Manag 2010, Volume 51,pp.1855-63.

11. Ahmadi MH, Mohammadi AH, Pourkiaei SM. "Optimisation of the thermodynamic performance of the Stirling engine." International Journal of Ambient Energy, 2014, DOI: 10.1080/01430750.2014.907211

12. Ahmadi MH, Mohammadi AH, Dehghani S. (2013) Evaluation of the maximized power of a regenerative endoreversible Stirling cycle using the thermodynamic analysis, Energy Conversion and Management, Volume 76, pp.561-570. 
13. Toghyani S., Kasaeian A., Ahmadi MH. (2014) Multi-objective optimization of Stirling engine using non-ideal adiabatic method. Energy Conversion and Management, 2014, Volume 80,pp.5462

14. Ahmadi MH, Ghare Aghaj SS, Nazeri A. Prediction of power in solar Stirling heat engine by using neural network based on hybrid genetic algorithm and particle swarm optimization. Neural Computing and Applications. 2013, Volume 22(6), pp. 1141-1150

15. Ahmadi MH, Hosseinzade H, Sayyaadi H, Mohammadi AH, Kimiaghalam F. Application of the multi-objective optimization method for designing a powered Stirling heat engine: design with maximized power, thermal efficiency and minimized pressure loss. Renew Energy 2013, Volume 60, pp.313-22.

16. Ahmadi MH, Sayyaadi H, Mohammadi AH, Marco A. Barranco-Jimenez. Thermo-economic multi-objective optimization of solar dish-Stirling engine by implementing evolutionary algorithm, Energy Conversion and Management, 2013, Volume 73, pp. 370-380.

17. Ahmadi, M. H., Sayyaadi, H., Dehghani, S., and Hosseinzade, H. Designing a solar powered Stirling heat engine based on multiple criteria: Maximized thermal efficiency and power. Energy Convers. Manage. 2013, Volume 75(1), pp. 282-291.

18. Sanchez E, Shibata T, Zadeh La. Genetic algorithms and fuzzy logic systems: soft computing perspectives. River Edge (NJ): World Scientific Publishing; 1997.

19. Kristinson K, Dumont G. System identification and control using genetic algorithms. J IEEE Trans Syst Man Cybern 1992, Volume 22(5),pp. 1033-46.

20. Koza J. Genetic programming: On the programming of computers by means of natural selection. Cambridge: MIT Press, MA; 1992.

21. Ahmadi MH., Ahmadi M.A., Mohammadi A.H., Feidt M., Pourkiaei S.M., Multi-objective optimization of an irreversible Stirling cryogenic refrigerator cycle, Energy Conversion and Management ,2014,Volume 82, pp. 351-360.

22. Ahmadi MH., Ahmadi MA., Mohammadi AH., Mehrpooya M., Feidt M., Thermodynamic optimization of Stirling heat pump based on multiple criteria, Energy Conversion and Management, 2014, Volume 80, pp.319-328.

23. Ahmadi MH., Dehghani S., Mohammadi AH., Feidt M., Marco A. Barranco-Jimenez., Optimal design of a solar driven heat engine based on thermal and thermo-economic criteria, Energy Conversion and Management, 2013, Volume 75, pp.635-642.

24. Rodriguez-Vazquez K. Multi-objective evolutionary algorithms in non-linear system identification. PhD Thesis, Department of Automatic Control and Systems Engineering, University of Sheffield, Sheffield, UK, 1999.

25. Ivakhnenko AC. Polynomial theory of complex systems. IEEE Transactions on Systems, Man and Cybernetics, 1971, Volume 1, pp. 364-78.

26. Farlow SJ. Self-organizing method in modelling: GMDH type algorithm. New York, Marcel Dekker, 1984.

27. Muller, J.A., Lemke F., Self-Organizing Data Mining. Libri, Hamburg 2000, ISBN 3-89811-8614 
28. Nariman-zadeh N, Darvizeh A, Felezi ME, Gharababei H. Polynomial modelling of explosive compaction process of metallic powders using GMDH-type neural networks and singular value decomposition. J Model Simul Mater Eng 2002, Volume 10, pp. 727-44.

29. Fonseca CM, Fleming PJ. Nonlinear system identification with multi-objective genetic algorithm. Proceedings of the 13th World Congress of the International Federation of Automatic Control. San Francisco, California: Pergamon; 1996, pp. 187-92.

30. Liu GP, Kadirkamanathan V. Multi-objective criteria for neural network structure selection and identification of nonlinear systems using genetic algorithms. IEE Proc Control Theory Appl 1999, Volume 146(5), pp. 373-82.

31. Nariman-Zadeh, N., Darvizeh, A., Ahmad-Zadeh, R., "Hybrid Genetic Design of GMDH-Type Neural Networks Using Singular Value Decomposition for Modelling and Prediction of the Explosive Cutting Process", Proceedings of the I MECH E Part B Journal of Engineering Manufacture,2003,Volume 217, pp. 779 - 790.

32. Porto VW. Evolutionary computation approaches to solving problems in neural computation. In: Back T, Fogel DB, Michalewicz Z, editors. Handbook of evolutionary computation. Institute of Physics Publishing and New York: Oxford University Press; 1997. p. D1.2:1-6.

33. Yao X., Evolving artificial neural networks. Proceedings of the IEEE, 1999, Volume 87(9), pp. $1423-47$.

34. Vasechkina EF, Yarin VD. Evolving polynomial neural network by means of genetic algorithm: some application examples. Complex Int 2001;9.

35. Ward, G. L. Performance characteristics of the Stirling engine. MSc thesis, University of Bath, 1972.

36. Prieto J.I, Gonzaalez M.A., Gonzaalez C, Fano. J. A new equation representing the performance of kinematic Stirling engines. Proc Instn Mech Engrs Part C,2000, Volume 214, pp. 449-464.

37. Nariman-zadeh N, Atashkari K, Jamali A, Pilechi A, Yao X. Inverse modelling of multi-objective thermodynamically optimized turbojet engines using GMDH-type neural networks and evolutionary algorithms. J Eng Optim 2005; Volume 37(5), pp. 437-62.

38. Yao, X., "Evolving Artificial Neural Networks", Proceedings of IEEE, 87(9), pp.1423-1447, (1999).

39. Atashkari K., Nariman-Zadeh N., Jamali A., Pilechi A., Thermodynamic Pareto optimization of turbojet using multi-objective genetic algorithm, International Journal of Thermal Science, ,2005, Volume 44 (11) ,pp.1061-1071.

40. Atashkari, K., Nariman-Zadeh, N., Golcu, M., Khalkhali, A., Jamali, A. Modelling and multiobjective optimization of a variable valve-timing spark-ignition engine using polynomial neural networks and evolutionary algorithms. Energy Conversion and Management, 2007, Volume 48 (3), pp.1029-1041.

41. Jamali, A., Nariman-zadeh, N., Darvizeh, A., Masoumi, A., Hamrang, S., 2009. Multi-objective evolutionary optimization of polynomial neural networks for modelling and prediction of explosive cutting process. Eng. Appl. Artif. Intell. ,2009, Volume 22 (4-5), pp. 676-687.

42. Lin JIE, Cheng CT, Chau KW. Using support vector machines for long-term discharge prediction. HydrologSci J. ,2006,Volume 51 (4), pp. 599-612. 
43. Gonzalez-Sanchez A., Frausto-Solis J., Ojeda-Bustamante W., "Attribute Selection Impact on Linear and Nonlinear Regression Models for Crop Yield Prediction," The Scientific World Journal, vol. 2014, Article ID 509429, 10 pages, 2014. doi:10.1155/2014/509429

44. Elçiçek H., Akdoğan E., Karagöz S., "The Use of Artificial Neural Network for Prediction of Dissolution Kinetics,” The Scientific World Journal, vol. 2014, Article ID 194874, 9 pages, 2014. doi: $10.1155 / 2014 / 194874$

45. Bildirici M., Ersin O., "Modeling Markov Switching ARMA-GARCH Neural Networks Models and an Application to Forecasting Stock Returns," The Scientific World Journal, vol. 2014, Article ID 497941, 21 pages, 2014. doi:10.1155/2014/497941

(C) 2014 by the authors; licensee MDPI, Basel, Switzerland. This article is an open access article distributed under the terms and conditions of the Creative Commons Attribution license. 